$$
\text { LA-SUB- }-95-83
$$

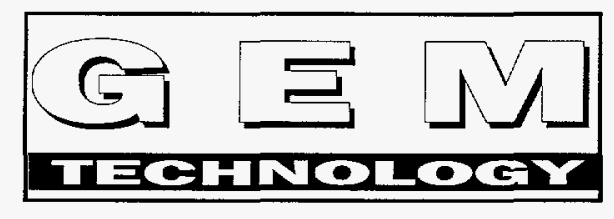

$$
\begin{aligned}
& \text { PECPIVED } \\
& \text { MAR } 2.51993 \\
& \text { OSTI }
\end{aligned}
$$

\title{
MARKET ASSESSMENT
}

\section{OF ENVIRONMENTAL ISSUES AFFECTING COAL USE \\ for}

\section{LOS ALAMOS NATIONAL LABORATORY}

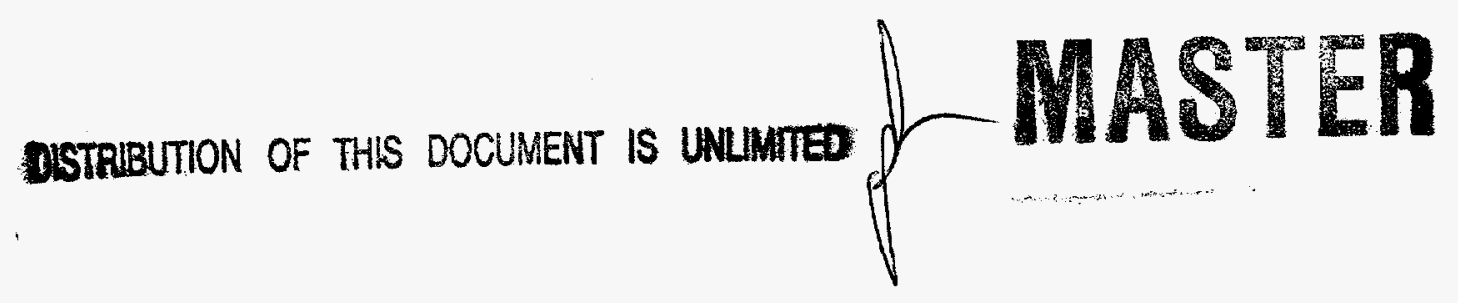

March 20, 1995 


\section{DISCLAIMER}

This report was prepared as an account of work sponsored by an agency of the United States Government. Neither the United States Government aor any agency thereof, nor any of their employees, makes any warranty, express or implied, or assumes any legal liability or responsibility for the accuracy, completeness, or usefulness of any information, apparatus, product, or process disclosed, or represents that its use would not infringe privately owned rights. Reference herein to any specific commercial product, process, or service by trade name, trademark, manufacturer, or otherwise does not necessarily constitute or imply its endorsement, recommendation, or favoring by the United States Government or any agency thereof. The views and opinions of authors expressed herein do not necessarily state or reflect those of the United States Goverament or.any agency thereof. 


\section{DISCLAIMER}

Portions of this document may be illegible electronic image products. Images are produced from the best available original document. 


\section{MARKET ASSESSMENT \\ OF ENVIRONMENTAL ISSUES AFFECTING COAL USE}

\section{Summary}

- This is a market assessment of environmental issues affecting coal use through 2020 . It was prepared by Los Alamos National Laboratories for the Fossil Energy R\&D Program. It is based on interviews of representatives of 8 coal, coal technology, electricity and environmental groups concerned with the future of energy and the environment.

- Interviewees generally agreed that the U.S. and other countries would continue to need to use coal into the middle of the next century. The size of the market for coal would be determined by the ability of coal and coal technologies to meet environmental requirements at costs that would compete with natural gas.

- Outside the U.S., three interviewees suggested that there is a market for low cost coal technologies that will reduce the environmental impact of coal use, particularly in developing countries that have few alternative sources of energy.

- The principal environmental concerns mentioned in these interviews were: efficiency and carbon, air toxics, and $\mathrm{NO}_{\mathrm{X}}$. Several also mentioned potential modifications to the $\mathrm{SO}_{\mathrm{X}}$ standards, a fine particulate standard, bottom and fly ash, and methane from coal beds.

- Several questioned whether pending regulatory activity in these areas might be suspended if risk assessment and cost benefit analyses are adopted as criteria for regulation.

- Interviewees generally favored continuation of research and development efforts that would improve the environmental performance and efficiencies of coal technologies while lowering their costs.

- Interviewees were generally more familiar with the environmental issues and the Clean Coal Technology Program than the Coal R\&D program. The two most familiar with the Coal R\&D Program (EPRI and NCC) referred to forthcoming reports for comments on coal technologies.

- Interviewees generally praised the accomplishments of the Clean Coal Technology program to date, particularly because it has demonstrated technologies with outstanding performance for $\mathrm{SO}_{\mathrm{X}}$ and $\mathrm{NO}_{\mathrm{X}}$ controls and with greatly improved efficiencies.

\section{Background and Methodology}

Los Alamos National Laboratory is providing this market assessment on environmental issues affecting coal use and research and development to the Fossil Energy Coal R\&D Program. The objective of this assessment is to appraise the likely role of coal as a source of energy in the U.S. and world in the 21st Century and to define the major environmental concerns that need to be addressed for coal to continue to be a critical 
component of energy supplies. The results of this assessment are to be used to define the environmental requirements that an effective Coal R\&D Program would need to address. It has been prepared to provide background for the Coal R\&D Program Strategic Plan that will be developed during FY1995.

The methodology used to prepare this assessment was based on interviews of representatives of coal, coal technology, electricity and environmental groups concerned with future energy and environmental requirements. Eight organizations participated, including the National Mining Association (NMA, formerly the National Coal Association), the National Coal Council (NCC), the Edison Electric Institute (EEI), the Electric Power Research Institute (EPRI), the Clean Coal Coalition (CCC), the Sierra Club, the Center for Clean Air Policy (CCAP) and the U.S. Environmental Protection Agency (EPA). All of the interviewees are located in Washington, D.C. and work closely with the legislative and regulatory processes affecting coal and the environment. Therefore, most interviewees were more familiar with environmental issues and the Clean Coal Technology Program than the specific activities of the Coal R\&D Program.

\section{The Role of Coal in the Twenty-First Century}

All but one interviewee (the Sierra Club) agreed that coal would be a key source of energy into the middle of the 21 st Century. They differed substantially on the share market coal would hold, with many agreeing that the more competitive coal and coal technology can be made in terms of total cost and environmental performance, the higher coal's likely market share. Stated another way, to preserve coal as a major energy option, the goal of a coal research and development effort should be to make the cost and environmental performance of coal as much like that of natural gas as possible.

Interviewees generally agreed that the U.S. would continue to use coal to produce electricity in the first quarter to half of the next century. EEI predicted that new coal fired electricity generating units would be ordered in the next two to five years. The question is how much market share will coal maintain over the longer term, given competition from gas, renewables and conservation.

The likely competition from conservation and other energy supplies is unclear. Several interviewees expressed concern that low cost natural gas supplies would not be sufficient to meet demand in the U.S. early in the next century. EEI indicated that the nuclear and hydro capacity is likely to diminish by 2010 because of relicensing problems for each. Most nuclear units are likely to be retired and the capacity of many hydro units is likely to be reduced to maintain flow. Both the Sierra Club and the CCAP believed that the contribution from conservation and renewables is likely to increase, because the conservation and renewable technologies are becoming more price competitive. EPRI and CCAP both cited the potential to use more biomass based technology as a competitor to coal. 
In international markets, interviewees indicated that many of the same potential competitors and similar uncertainties exist. Three (CCC, EPA, and CCAP), however, indicated that increased coal use is highly likely in developing countries such as China, Pakistan and India and parts of the former Soviet Union.

On the subject of non-utility coal use, two interviewees (NCC and NMA) saw the potential for increasing U.S. coal use in non-electricity markets. CCC stated that domestic use of liquefaction is not politically viable at this time and the Sierra Club argued strongly against expanding coal use to new sectors. Two interviewees (CCC and EPA) cited increasing coal use in developing countries (e.g. China and India) as potential markets for non-electricity sector coal technologies.

The representatives of the environmental community agreed that the scientific evidence supporting the global climate change theory is mounting, while NCC felt that it was declining. The Sierra Club argued that all coal use will need to cease by 2020 if we are to reduce carbon emissions to 30 percent of 1990 levels, a goal that some in the environmental community advocate to reverse the effects of global climate change. The Center for Clean Air Policy and EPA indicated that a more gradual approach to moderating contributors to global climate change would be likely, given the high economic and social costs of reduced fossil fuel use. Under their scenarios coal use would decrease as we approach the middle the 21 st century and natural gas would be phased out later.

\section{Critical Environmental Issues for Coal as We Approach 2020}

Interviewees generally agreed that the global issue of carbon and efficiency and the more regional issues of $\mathrm{NO}_{\mathrm{X}}$ and air toxics are the major environmental challenges facing coal over the next 25 years. There was some disagreement on the ranking of these, nevertheless.

\section{Global Issues -- Carbon and Efficiency}

Efficiency and carbon emissions provide the greatest technical and economic challenge. While the environmental representatives believe scientific evidence supports the global climate change theory, representatives of the coal and electricity community typically described global climate change and the efforts to reduce carbon and methane emissions as international political issues. Most believed that control of contributors to global warming (e.g. carbon and methane) would not be in effect by 2020 because they felt that the science or public and political perception of risks would not support the imposition of high (social and economic) cost strategies.

Nevertheless, most interviewees viewed higher efficiency as critical to reducing the cost of coal use to allow it to be more competitive. Interviewees generally agreed that coal fired units will need to be more efficient and lower cost if they are to compete with gas. 
(The exception is NMA, which expressed concern that higher efficiencies could mean less coal use.)

In addition, higher efficiencies would reduce carbon emissions and therefore are a critical component of a strategy to reduce the contributors to global climate change, if and when such a strategy is imposed. Also, EPA indicated that setting efficiency targets would be a relatively low cost way of reducing emissions that contribute to global climate change effects.

NMA and CCAP also named post combustion carbon dioxide control technologies as potential means to reduce the emission of carbon associated with coal. Both understood the weaknesses of those technologies to date, but believed progress with developing technologies that capture carbon dioxide would be beneficial to coal use.

\section{Regional Issues -- Air Toxics, $N O_{X}, S O_{X}$, Fine Particulates and Solid Wastes}

Additional regulation of air toxics, $\mathrm{NO}_{\mathrm{X}}, \mathrm{SO}_{\mathrm{X}}$, fine particulates, and solid wastes are also uncertain, primarily because the imposition of risk assessment and cost benefit analyses requirements might prove the proposed additional regulations too costly to impose. However, until new criteria are established and implemented, there are pending regulatory actions that make these the most immediate regulatory challenges that coal faces.

Regulation of air toxics and its impacts appear to be uncertain. Mercury appears to be the most likely to be controlled, but this will not be clear until the ongoing studies required by the Clean Air Act are completed. Some interviewees were concerned that other heavy metals and chlorine would be included.

The impact of air toxic regulations is also uncertain. Because the volume of emissions varies by the type of coal, it is not clear how extensive the impact will be. CCAP mentioned that Appalachian coal tended to be higher in mercury, while Rocky Mountain coal tended to have lower mercury content and therefore might be a good substitute. EEI indicated that baghouses and scrubbers might mediate the effects, but most powerplants have precipitators and no scrubbers. CCAP commented that scrubbers are only about $20 \%$ efficient in removing mercury because it vaporizes at $75^{\circ} \mathrm{F}$.

The comments on $\mathrm{NO}_{\mathrm{X}}$ indicated that most considered further control likely if risk assessment and cost benefit standards are not imposed. The reasons varied but in sum the conclusion was that the combination of concerns about acid rain, ozone attainment, visibility, and the precipitation of nitrogen oxides into water bodies would cause further control of this compound.

At this point, it is far less expensive to reduce a ton of $\mathrm{NO}_{\mathrm{X}}$ emissions from stationary sources such as powerplants than to impose further VOC (volatile organic carbon) 
controls on automobiles and other mobile sources. According to EEI, the marginal cost of powerplant $\mathrm{NO}_{\mathrm{X}}$ control is $\$ 2000$ per ton while the marginal cost of VOC reduction is $\$ 15,000$ per ton. In addition, CCAP reported that studies of $\mathrm{NO}_{\mathrm{X}}$ transport and ozone formation indicate that ozone non-attainment in cities like Chicago is in part attributable to $\mathrm{NO}_{\mathrm{X}}$ emissions and ozone that are carried into the region from stationary sources located in attainment areas, such as the Ohio River Valley.

Risk assessment and cost benefit analysis based standards could foreclose or at least limit further control of $\mathrm{NO}_{\mathrm{X}}$ because additional control would be particularly expensive for existing facilities. According to EPRI, low $\mathrm{NO}_{\mathrm{X}}$ SCR units ( $85 \%$ efficiency) have been developed, but they are expensive.

In addition, selected interviewees mentioned a potential short term $\mathrm{SO}_{\mathrm{X}}$ standard or changes in $\mathrm{SO}_{\mathrm{X}}$ standards resulting from re-opening the Clean Air Act, fine particulate matter, methane from coal mines, solid waste (bottom ash and fly ash), and the adverse public perception of coal as major issues. Again, commenters pointed out that adoption of risk assessment and cost benefit methodologies could change the likely level of control of these pollutants.

\section{Coal R\&D Program Activities}

Interviewees varied considerably on their knowledge of Coal R\&D program activities and somewhat on their evaluation of it. All but one interviewee (the Sierra Club) agreed that research and development of cleaner, more efficient and lower cost technologies should continue. Of these, all saw a continuing role for the government, but two (NCC and EPA) also felt that the private sector should take more responsibility for coal technology commercialization.

Summary statements of several participant's overall view of the goals for the Coal R\&D program are:

- EPRI has stated that the Coal R\&D Program should continue to develop a portfolio of technologies because the uncertainty about fuel prices and environmental requirements makes it difficult to decide which technologies are likely to be needed. Additional comments on the Program, consistent with EPRI's views, are reflected in the forthcoming National Research Council report.

- CCAP shared a similar view, encouraging continued development of cutting edge technologies such as carbon absorption.

- NCA encouraged a broad research program, including work on carbon absorption, air toxics liquefaction and coal refineries. Products of interest include: transportation fuels, ammonia, fertilizer, feedstocks and cleaner fuels for electricity generation.

- EEI focused its comments on reducing costs, raising efficiencies, reducing unit size and lowering emissions so that coal can compete in a deregulated market. 
- NCC will be issuing a report, "Coal Utilization Technology", in the next few months that will reflect its views on coal technology development. Drafts indicate that they will support the continuation of basic research and the use of incentives to commercialize technologies.

- CCC encouraged development of cost effective small units for dispersed systems. It also stated that new technologies must have superior performance and cost characteristics to counterbalance the increased operational risks if they are to be broadly adopted. It cited LEBS and hot gas clean-up as examples of R\&D efforts which could reduce the costs of using advanced technologies.

Three participants (CCC, CCAP, and EPA) recommended that consideration be given to committing at least part of the Program to the needs of the developing countries that will continue to be dependent on coal (e.g. India, China, Pakistan and parts of the former Soviet Union). These markets need low cost technologies that are efficient and significantly reduce emissions. Both CCC and CCAP noted increased equipment sales to these countries would be beneficial to the balance of trade and could increase employment in the U.S. CCC suggested that the most effective strategy might be to upgrade the efficiency of pulverized coal units and lower the cost of environmental control technology. CCC saw potential for increasing use of non-utility coal technologies, such as coal derived methanol and pipeline quality gas.

Comments on specific elements of the Program varied. Interviewees suggested that the program activities to address air toxics be reviewed by those that are familiar with the potential needs. Several believed that additional work on coal chemicals and coal preparation technologies might be useful in addressing potential toxics problems. Only two interviewees (EPRI and NCC) were aware of activities to develop bioremediation technologies to reduce the environmental effects of coal use. None were aware of efforts to use microwave as a pretreatment technology.

At least four stated that the Coal R\&D Program and Clean Coal Technology Program, respectively, had been very successful in developing and demonstrating technologies to control $\mathrm{SO}_{\mathrm{X}}$ and $\mathrm{NO}_{\mathrm{X}}$. Most interviewees suggested that the issue now was not the availability of such technologies, but the cost of using them. Interviewees also discussed the success of the Coal R\&D and CCT Program in terms of improving thermal efficiency. Again, the cost of deploying these new technologies appeared to be the concern.

\section{Conclusion}

According the interviewees participating in this market assessment, the future of coal as a major energy resource is uncertain. Additional technologies to improve the environmental and cost performance of coal use are needed. Without substantial gains in environmental, efficiency and cost performance, coal will not be able to make its full contribution to future energy supplies. 


\section{Contacts Suggested by Interviewees for Future Discussions}

Source

NCA

NCC

EEI

EPRI

CCAP

Sierra Club

EPA

\section{Suggested Contact and Affiliation}

- EPA (Policy: Karl Hausker; Air Programs: Mary Nichols; Global Climate Change: David Doneger)

- Destech; Texaco; Shell (IGCC Suppliers)

- AEP: Murkowski (PFBC)

- Southern Company: Bob Woodall (Air Toxics)

- EPRI

- MAPCO: Joseph Craft

- North American Coal: Cliff Miercourt

- Bechtel: Jerry Oliver

- Consultant: Duane Spencer

- IES Industries: Renee Males

- Dr. Bill Harrison

- Alison Corporation: Sy Ali

- EEI: Chuck Linderman

- Clean Coal Coalition: Ben Yamagata

- EPRI: David Escanazi

- Tampa Electric Company: Steve Jenkins

- EPRI Generation Group: George Preston

- EPRI Strategic Development Group

- EPRI: Kurt Yager

- Wisconsin Electric Power and PacifiCorp

- John Sununu

- Consolidation Coal: Dick Kearch

- Massey Coal: Jerry Eister

- Arco Coal: Terry O’Connell

- NRDC: David Hawkins

- League of Conservation Voters: Jim Matty

- World Resources Institute: Roger Dower

- Research Cotrell (emissions trading)

- Friends of the Earth: Ralph DiGenero

- U.S. PIRG: Ann Aurelio

- Alliance to Save Energy

- American Council for an Energy Efficient Economy: Howard Geller 
DRAFT Note from Interview with Ben Yamagata -- January 11, 1995

Van Ness Feldman, P.C. (Clean Coal Coalition and International Energy Development Council) Page 1

\section{Critical Environmental Issues for Coal as We Approach 2020}

Critical environmental issues facing coal are: (1) toxics; (2) probably carbon dioxide; (3) the perception that coal adversely affects the environment; and, (4) phased introduction of new technology. To summarize, the visible bad actors have been dealt with but the invisible bad actors are now the issue.

On the issue of toxics, the interviewee commented that those that understand the likely structure of toxics regulation should be asked to comment on whether the Coal R\&D Program is adequately addressing those issues. He suggested John Wooten of Peabody as a contact for this question and other technical issues raised in this interview.

On the subject of carbon dioxide, the interviewee emphasized that the potential for regulation in this area was highly dependent on international politics. If countries strongly advocating reduction of greenhouse gas emissions should prevail in this debate, regulations will require improved combustion efficiencies to permit coal to perform like natural gas and other competitors. Being able to accomplish this at a competitive cost is an important consideration.

Examples of Coal R\&D programs that appear to be addressing efficiency and cost concerns are the Low Emission Boiler Systems (LEBS) program being conducted at PETC and the hot gas cleanup program, which could reduce the cost of using advanced technologies, such as PFBC and IGCC.

The interviewee also commented on the detrimental effect of the perception that coal adversely affects the environment, despite considerable success to date in removing the obvious (i.e. visible and odorous) effects as well as $\mathrm{SO}_{\mathrm{x}} \mathrm{NO}_{\mathrm{x}}$, and $\mathrm{CO}$. He cited the work of CEED and suggested an assessment of whether their program is positively affecting the image of coal.

An example of the importance of coordination of environmental regulation and the development of appropriate environmental technologies is the experience of the 1970's and 1980's. During that time, manufacturers took the risks of developing technologies and users often experienced significant costs and problems when they were installed. Wet scrubbers, for example, were expensive and often had operational problems. This is an example of the cost of not synchronizing the state of the technology and the environmental regulations. Environmental laws did not recognize the high cost of rapid adoption of a developing technology.

\section{Identifying the Market for Environmental Technology}

The interviewee identified two distinct markets for cleaner coal technologies (1) the domestic market and (2) the international market. In the domestic market, electricity generators and equipment suppliers are the primary clients for cleaner coal technologies. The restructuring of the electricity industry is raising a host of uncertainties in these markets. Two of the more obvious, central station versus dispersed systems and repowering of aging stations, will directly affect coal use. If dispersed technologies are favored, coal will be disadvantaged unless the means to use it in smaller units are developed. Repowering existing facilities should favor coal since the sites are already permitted. 
DRAFT Note from Interview with Ben Yamagata -- January 11, 1995

Van Ness Feldman, P.C. (Clean Coal Coalition and International Energy Development Council)

Page 2

Currently, the increased use of natural gas in the domestic market and the political environment, which is advocating a lesser federal role in coal technology development, can be expected to slow the adoption of advanced coal technologies. New technologies like IGCC could become competitive from a cost standpoint but customers are concerned about operational risks and therefore continue to favor conventional technologies. New technologies will need to have superior cost and performance characteristics before they are broadly adopted.

The likelihood that coal use will be expanded in the domestic non-electricity sectors is low. Liquefaction is not politically viable at this time.

The international market, in contrast, is driven by cost considerations with less emphasis on environmental performance. The countries that are expected to continue to heavily rely on coal include: China, India, Pakistan, and some of the NIS. In this market, low cost, efficient technologies are the likely winners. If the U.S. government is seeking to improve environmental performance in these countries and increase U.S. equipment sales, the most cost effective strategy may be to assist equipment manufacturers in upgrading existing pulverized coal technology to improve its combustion efficiencies and limit the cost of environmental control technology.

The potential for using low cost technologies or penetrating non-electricity markets is larger in the international market. For example, coal derived methanol may be an important transportation fuel in countries with large coal resources but small oil reserves. Or, in China, for example, medium BTU gas may have a significant potential role. This potential is created by the lack of existing transportation infrastructure and the limited availability of alternatives to coal. Constructing facilities to produce coal derived gas may have lower costs than constructing conventional rail transportation. In addition, coal derived gas could be the basis for producing chemical feedstocks as well as being an energy source.

\section{Role of Coal in the Twenty-First Century}

In the domestic economy, the dominant sector for coal use will continue to be electricity. That does not necessarily mean that coal will be used at the same intensity that it is used today, i.e. producers cannot assume that "coal will come back" as natural gas reserves are exhausted. Changes in demand patterns that would make U.S. consumption intensity more like that of European countries would probably reduce coal use. Changes in the supply mix, e.g. fusion or hydrogen based electricity, would also tend to suppress coal use.

In developing countries (China, Pakistan, and the former NIS, for example), the role of coal may actually be greater as the demand for electricity grows and the potential for using coal derived feedstocks and fuels in transportation expands. 
DRAFT Note from Interview with Ben Yamagata -- January 11, 1995

Van Ness Feldman, P.C. (Clean Coal Coalition and International Energy Development Council) Page 3

\section{Successes in Coal R\&D Program}

The Coal R\&D Program has been quite successful in developing and demonstrating technologies for controlling $\mathrm{SO}_{\mathrm{x}}$ and $\mathrm{NO}_{\mathrm{x}}$. When you have achieved $98-99 \%$ reduction and are equaling the costs of conventional technologies, you have achieved a great deal. 
DRAFT Notes from Interview with Rob Long -- January 12, 1995

National Coal Association

Page 1

\section{Critical Environmental Issues for Coal as We Approach 2020}

The critical environmental issues for coal that can be addressed in the Coal R\&D program include:

- SO $x$ and NO x: We can expect to live with the Clean Air Act but we must be aware that proposals to reopen the CAA may affect Phase II standards, even though the primary focus today is on mobile source standards.

- Air Toxics: The mercury study is underway, as mandated by the CAA. Other heavy metals and chlorine may also be included. The approach to all of these will be affected by debate on regulatory reform and improving risk assessment methods. The risk standards in the CAA my not be justifiable if subject to a cost effective evaluation. The one part per million standard is viewed as excessive.

- Climate Change: The science surrounding this issue is uncertain, but the issue is not likely to go away. This is a domestic and international issue that is already affected by the Climate Treaty.

- Coal Ash: RCRA has not affected coal ash and disposal, but the R\&D program needs to be aware of the potential for regulation of coal ash in the future.

The other critical environmental issues for coal are production related issues. These include:

- Water: Management of acid mine drainage, groundwater contamination and storm water runoff are major issues for coal mining. The are hard to control and monitor. The Safe Water Drinking Act is presenting a new challenge as it is pushing the analysis of water quality into the analysis of groundwater and its affect on drinking water.

- Wetlands: The strict definition of wetlands (presence of water for 14 days per year or more) is presenting challenges for mine operators. Wetlands regulation prevents mining in these areas or even running trucks through them.

\section{Effectiveness of Coal R\&D Program in Addressing these Issues}

Rounds 4 and 5 of the Clean Coal Technology Program addressed combustion efficiency in addition to the SO $\mathrm{x}$ and NO $\mathrm{x}$ criteria used in rounds 1-3. Deployment of these technologies would provide a huge leap in thermal efficiency-- from $30-35 \%$ to $40 \%$ plus. Some research may be needed to drive down the front end cost of the new technologies. While IGCC appears to have life-cycle costs that are comparable to conventional PC units, the high initial capital costs are a barrier to their adoption. Driving down these costs may be an appropriate federal activity.

Additional research on technologies that promise to be efficient may also be justified. For example, would the cost of MHD preclude its development now that efficiency is a concern?

NCA is concerned about technologies that would improve combustion efficiencies and thereby reduce coal use. It therefore sees value in technologies that would dispose of $\mathrm{CO} 2$, but it is not aware of technologies under development that appear to have widespread application. A continuing research effort is suggested.

Additional work in air toxics and liquefaction are also recommended. 
DRAFT Notes from Interview with Rob Long -- January 12, 1995

National Coal Association

Page 2

\section{Successes in the Coal R\&D Program}

The Coal R\&D program has successfully addressed SO $\mathrm{x}$ and NO $\mathrm{x}$ control technologies. Advanced coal cleaning, combustion, and post-combustion technologies have demonstrated $99 \%$ percent removal for these effluents.

\section{Role of Coal in the Twenty First Century}

Overall, the coal producer is focusing on its traditional market--electricity generation-- and expects the industrial market to continue to decline. Coal should resume its growth in the electricity sector in the next decade.

From a longer term perspective, concerns about energy security suggest that liquefaction and coal refineries may be important. Products of interest include: transportation fuels, ammonia, fertilizers, feedstocks as well as cleaner fuels for electricity generation.

\section{$\underline{\text { Suggested Contacts }}$}

- EPA (Policy: Karl Hausker; Air Programs: Mary Nichols; Global Climate Change: David Doneger)

- IGCC Suppliers (Destech; Texaco; Shell)

- PFBC (AEP: Murkowski)

- Air Toxics (Southern Company: Bob Woodall)

- EPRI 
DRAFT Notes from Interview with Robert A. Beck -- January 19, 1995

Edison Electric Institute

Page 1

\section{Critical Environmental Issues for Coal as We Approach 2020}

The major issue affecting coal's position in 2020 is cost and the ability to compete with alternative sources of electricity in a more competitive environment. With existing technologies we can control SO $x$ at 95-97\% and new technologies have demonstrated control at $99 \%$. NO $x$ controls are also available. In the shorter term, we can expect some challenges to the current regulations that might cause more stringent controls than we currently have. For example:

- The ambient air quality standard for $\mathrm{SO}_{2}$ could be changed from a 24 hour standard to a 5 minute standard. This is an enforcement driven proposal that would cause some plants currently in compliance to fall out of compliance and therefore require controls beyond those expected for the acid rain compliance strategies.

- The $\mathrm{NO}_{\mathrm{x}}$ emissions requirements could be changed by provisions to improve attainment of ozone ambient standards in non-attainment areas. The 100 largest cities in the U.S. are all classified as non-attainment for ozone (Class III and IV). Further reductions in VOC's and $\mathrm{NO}_{x}$ are likely to be required. If this is so, mobile sources (primarily VOC) and stationary sources are likely to be more stringently controlled. Power plants could be required to add additional $\mathrm{NO}_{x}$ emission control. The marginal costs of $\mathrm{NO}_{x}$ controls is about $\$ 2000$ per annual ton of reduction whereas the marginal cost of VOC reduction is $\$ 15,000$ per ton. Despite this difference in cost, $\mathrm{NO}_{\mathrm{x}}$ is not likely to be the only target for controls as VOC's have greater effect on ozone formation on a ton basis.

- Control of air toxics from coal fired powerplants are uncertain. EPA is completing the studies on mercury and all toxics emitted from powerplants, as required by the Clean Air Act. The principal areas of concern for coal are mercury, arsenic, and selenium, all of which are volatilized at low temperatures. Coals vary substantially in their content of these elements. Therefore the problems tend to be regional. If the facility is equipped with scrubbers, these toxics are captured in the quenching process. It appears that baghouses also capture these toxics. However, most coal fired powerplants are not equipped with either scrubbers or baghouses. It should also be noted that passage of H.R. 9 (a statute requiring risk assessment and cost benefit analysis for all environmental regulations) could change the potential effect of air toxics regulation.

- Control of $\mathrm{CO}_{2}$ is not a major impending issue for the United States but is an international trade issue. At this point, environmental science is not driving the issue; international politics are. Voluntary actions on the part of the U.S. utilities have helped to alleviate the pressures in the United States. The Secretary of Energy and the heads of the utility trade associations have signed an MOU to reduce contributors to global climate change. About 115 utility executives are expected to sign individual MOU's to implement the agreement.

\section{The Critical Issue for Coal Is Cost}

The environment per se is not keeping coal out of the market place; environmental standards have never stopped a coal fired powerplant. It is the cost of building a coal fired powerplant and the forces of competition that will limit coal's contribution. We can expect coal prices to continue to be lower than natural gas prices and gas prices to rise at a faster rate than coal. Nevertheless, coal will find it difficult to compete with gas if it cannot be built in smaller increments, with higher 
DRAFT Notes from Interview with Robert A. Beck -- January 19, 1995

Edison Electric Institute

Page 2

efficiencies, lower emissions, and lower costs. Efficiency targets are not needed because the market, the need for lower costs, will drive the need for efficiency. Utility constructors will want coal, but they will want to be able to build it in 18 months to keep costs down, they will want it to be cleaner and smaller so that it can be close to the load center, and they will want it to be more efficient so that operating costs are lower.

\section{Effectiveness of Coal R\&D Program in Addressing Environmental Issues}

The Coal R\&D program has successfully addressed the control of SO $x$, NO $x$, and TSP. Cool Water is an example of a successful demonstration of the use of a clean fuel. The program has not focused on metals, but may want to consider more work on coal chemistry and coal pretreatment and combustion processes to reduce metals and other pollutants, especially given that burning coal as a powder is still the cheapest alternative.

\section{Role of Coal in the Twenty-First Century}

Coal must be prepared to hold 45-50 percent of the utility market in 2010 (in comparison to 55 to 60 percent demonstrated recently). This assumes high penetration of natural gas and some renewables. The nuclear and hydro share of the market are likely to be down because of environmental constraints. Most of the existing nuclear plants will pass 30 years of operation by 2008-2012 and unless the waste issue is resolved it is not clear how many rebuilds or new units will be allowed. Relicensing of hydro units is also being challenged since flow has become an environmental issue. While hydro will continue to be available, operating rates are likely to be reduced to lower flow rates and to protect fish.

In the next 2-3 years, commitments will be made to new coal powerplants. By this time, some of the information from the Clean Coal Technology Demonstration will be in and will influence the selection of technology. Coal will continue to be a low cost source of electricity. Also important is that "Coal is power from America for America".

\section{Suggested Contacts}

- EEI (Chuck Linderman)

- Clean Coal Coalition (Ben Yamagata)

- EPRI (David Escanazi)

- TECO (Steve Jenkins) 
DRAFT Notes from Interview with James McAvoy -- February 14, 1995

National Coal Council

Page 1

\section{Critical Environmental Issues as We Approach 2020}

The major environmental concerns for coal are: emissions related to global climate concerns, air toxics, and $\mathrm{SO}_{\mathrm{X}}$ and $\mathrm{NO}_{\mathrm{X}}$. A second level concern is solid waste and water, but even this concern could wane as pressure on reducing unfunded mandates increases.

From a regulatory perspective, the potential for adding risk analysis and cost effectiveness analyses to the process could moderate the likelihood of further excessive regulation for these pollutants. For example, further analyses could moderate the pressure for additional $\mathrm{SO}_{\mathrm{x}}$ and $\mathrm{NO}_{\mathrm{x}}$ control. In addition, mounting scientific evidence suggests that global climate change is not as threatening as some believe and the potential for controlling carbon is causing conflict between developed and developing countries. Developing countries are insisting that the developed countries absorb the cost of reducing contributors to global climate change and the Europeans appear to be resisting.

Efficiency targets are likely and we can expect industry to press ahead on efficiency.

\section{Priorities for the Coal R\&D Program}

The critical coal research priority is substantial improvement of advanced coal cleaning and basic research. (NCC is currently preparing recommendations on the federal role in the development and commercialization of advanced technologies. Measures being considered include tax relief, other incentives and insurance for new technologies, as well as continuation of the current coal R\&D program.)

With additional research, coal can comply with additional standards and remain competitive. An example of this type of technological and economic progress can be found in the U.S. copper industry, where, with the advance of technology, previously closed mines are being reopened and are competing with higher quality resources in Latin America.

The forthcoming NCC report on Coal Utilization Technology: A Critical Review will comment on advanced technologies such as biological coal cleaning, among others. A draft of this report (not for attribution) will be available in March and the formal copy will be available in June.

\section{Role of Coal in the Twenty First Century}

Coal is a low cost fuel that reduces dependence on imported energy. Coal will continue to play a significant role in power generation and displace oil and gas in some other applications. An economic coal engine and environmental and economically sound home coal systems, like those demonstrated in the United Kingdom can be deployed. The challenge is for coal to reach its full potential of cost-effectively meeting the energy needs for which it is suited. Deploying cleaner coal technologies is important to realizing the value of coal to the U.S. economy and reducing the environmental impact of its use. New coal technologies with higher efficiencies, lower emissions, and lower capital costs are necessary to help coal make its full contribution.

\section{Key Players and Suggested Contacts}


DRAFT Notes from Interview with James McAvoy -- February 14, 1995

National Coal Council

Page 2

The key players in developing clean coal technologies are the government (including its university contractors) and industry. To some extent, government presence has displaced industry involvement. For example, as the government coal program grew in the 1970's and 1980's, programs like the Bituminous Coal Research Center (in Pittsburgh) were closed and NCA eliminated its position of Vice President for Research. Now, we need to consider what industry is willing to do, given the recent political changes and likely budgetary changes.

Suggested contacts for further discussion include:

- Joseph Craft III (MAPCO)

- Cliff Miercourt (North American coal)

- Jerry Oliver (Bechtel)

- Duane Spencer (consultant)

- Renee Males (IES Industries)

- Dr. Bill Harrison (Retired)

- Dr. Sy Ali (Alison Corporation) 
DRAFT Notes from Interview with Alex Cristofaro -- January 26, 1995

U.S. Environmental Protection Agency

Page 1

Critical Environmental Issues for Coal as We Approach 2020

The major environmental issues confronting coal over the next 25 years are:

- $\mathrm{NO}_{\mathrm{x}}$

- $\mathrm{CO}_{2}$

- Methane from coal mines

- Toxics (particularly mercury)

- Possibly fly ash and bottom ash

The most important of these is carbon dioxide, but the degree to which emission limits will be imposed in this timeframe is unclear. The scientific evidence of global climate change is mounting and strategies to address the issue will be considered. The question is whether we will reach a consensus on how to address the issue in twenty five years, given the social and economic constraints on possible control strategies.

The potential for process efficiency targets as a strategy to address global climate change issues is strong. While EPA has never set efficiency standards, standards would be a mechanism to establish cost competitive strategies for carbon dioxide control. Efficiency standards might be an easier action to take than other alternatives to control contributors to global climate change and could occur in the 25 year time frame of this study.

Nitrogen oxides are also an area of concern. Not only are nitrogen oxides a concern for nonattainment areas, but nitrogen oxide deposition is an emerging major issue. Precipitation of nitrogen oxides from the air and deposition in water is contributing to excess nitrogen load in water bodies. Power plants are major point sources of nitrogen oxides and therefore are subject to further control, without regard to the ambient air quality attainment status of the basin where the power plant is located.

Mercury control is likely to be a concern once the ongoing studies are completed.

While coal ash (bottom ash and fly) ash are unlikely to be classified as hazardous wastes, the potential should be kept in mind.

\section{Effectiveness of Coal R\&D Program in Addressing Issues}

The interviewee declined to comment on the effectiveness of the Coal R\&D program, responding that it was impossible to separate the effect of the program and the actions that would have been taken without the program.

\section{Role of Coal in the Twenty-First Century}

The future of coal as an energy resource in the United States is dependent on overcoming its technology limitations. The U.S. will need coal for electricity in 2020 , but the size of the market is unclear. To compete with natural gas, it must be as similar to gas in cost and environmental performance as possible. The more comparable coal is to natural gas, the higher the likely market share for coal. 
DRAFT Notes from Interview with Alex Cristofaro -- January 26, 1995

U.S. Environmental Protection Agency

Page 2

Outside of the United States, it is clear that some countries will be heavily dependent on coal. It may be in the interest of the United States to promote clean coal technology for countries like China and India.

Suggested contacts:

Alliance to Save Energy

American Council for an Energy Efficient Economy: Howard Geller 
DRAFT Notes from Preliminary Interview with David Eskinazi -- February 13, 1995

Electric Power Research Institute

Page 1

\section{Critical Environmental Issues for Coal as We Approach 2020}

The critical environmental concerns that are local and regional in nature are (in order of importance):

- Air Toxics -- The effects at a local and national level are not well understood. More analysis of the risks and methods to manage (alternative technologies) are needed..

- $\mathrm{NO}_{\mathrm{x}}$-- Concerns about $\mathrm{NO}_{\mathrm{x}}$ are driven by three broader considerations--acid rain, ozone non-attainment, and visibility. All three will affect the required level of control.

- Solid Waste -- Comparable to $\mathrm{NO}_{\mathrm{X}}$ in importance.

On a global level, carbon content in fuel is important.

The trend is toward higher efficiency combined with refuse use (e.g. biomass gasification) and pollution prevention to reduce carbon emissions. We will continue to need process improvements to get us into 50-60 percent efficiency ranges.

It is important to keep R\&D focused on new technology to meet these needs despite the current lack of activity in ordering new capacity.

\section{Coal R\&D Program Activities}

It is important to continue to develop a balanced portfolio of technologies, because we do not know what fuel prices will be. All aspects of the program are important, given the uncertainty.

For new installations, we need continued development and application of advanced cycle technologies. For existing installations, technologies for additional air toxics, $\mathrm{NO}_{\mathrm{x}}$ and fine particulate control are important. Integrated emission management will become more important.

Bioremediation studies are being conducted, but the interviewee was not aware of work with microwave technology as it applies to coal.

Additional comments on new technologies were incorporated in the National Research Council Report, which is not yet publicly available.

\section{Expected Availability of New Technology}

Several technologies are available to control the problems we expect over the next 10-15 years, but the costs are still a consideration in their use. Examples include IGCC, where greater penetration will depend on lowering costs. Another example is $\mathrm{NO}_{\mathrm{x}}$ retrofit, where $\mathrm{SCR}$ systems $(85 \%$ reduction) have been developed, but they are expensive. Incremental cost reductions of $\mathrm{SO}_{\mathrm{X}}$ controls should also be sought. For air toxics, the uncertainty about which species may be regulated make it difficult to assess the specific needs. 
DRAFT Notes from Preliminary Interview with David Eskinazi -- February 13, 1995

Electric Power Research Institute

Page 2

\section{Role of Coal in the Twenty-First Century}

We can expect to need to use coal based generation well into the 21st Century. The share for coal will be dependent on relative fuel prices. Since those prices are highly uncertain, we need to maintain the Coal R\&D program to be ready for an uncertain future. The National Research Council report contains additional comments on this issue which should be considered.

\section{Key Players and Suggested Contacts}

The key players in the development of coal technologies are DOE, EPRI, equipment manufacturers, the electric utilities and the coal industry.

The responses to this interview include the perspective of George Preston, Vice President for the Generation Group. As this planning activity continues, additional work with this office and the Strategic Development Group may be beneficial. 
DRAFT Notes from Preliminary Interview with Dan Becker--February 21, 1995

The Sierra Club

Page 1

\section{Critical Environmental Issues for Coal as We Approach 2020}

The most critical environmental issues for coal as we approach 2020 are:

- Global warming

- Sulfur and nitrous oxides

- Sludge and scrubbers (toxic and solid wastes)

- Mining related hazards (coal seam methane, surface disruption, worker hazards)

The last three of these will need to be dealt with over the next 25 years but by 2020 we will need to greatly reduce combustion to reduce carbon emissions. Since carbon dioxide cannot be scrubbed, coal use must cease. By 2020, coal will be a useless commodity. The abundance of coal argument will not override long term concern about the effects of coal use. According to the IPCC and emerging science, we will need to cut carbon emissions to $30 \%$ of 1990 levels to protect the environment. We are finding it difficult to cut emissions to 1990 levels, but we must move forward if we are to prevent further deterioration of the global environment.

Currently, public concern about global warming may appear to be waning but these issues will reemerge. People see environmental issues as inter-related. During the summer of 1988 they were clearly aware of environmental problems because it was very hot and dry, the smog was severe, and the beaches were polluted.

Recent evidence of long term global warming trends include:

- Satellite data on sea-level rise (500,000 data points) indicate that sea level is rising.

- Data on Alpine systems indicate that Alpine flowers are dying because of higher temperatures.

- Increasing presence of carbon dioxide is allowing woody species to overtake native species in the tropics.

- El Nino is linked to global warming; the floods in Europe are evidence of higher temperatures.

- Tropical diseases are broadening with global warming, as evidenced by studies at Harvard and the Netherlands Public Health Ministry. The Ministry estimates that there will be 1 million additional deaths from malaria in 2030 as the result of global warming.

The evidence indicates that global warming will be devastating. Once it is recognized, citizens will demand a response and the number of options will be limited. One of the most obvious will be to stop burning. Proposals like increasing coal use in transportation are unacceptable because they will increase pollution.

\section{Energy in the Twenty-First Century}

We have had considerable success in increasing energy efficiency. Demand side management programs have been successful. Efforts to repeal DSM will not be successful. There has been less success with cars (we have not achieved a 45 mile per gallon standard), but there will be more progress in the next phase.

The solution to the global warming problem is to back out fossil fuels, first coal and then natural gas. Energy efficiency and renewable technology can be substituted and their contribution to total 
DRAFT Notes from Preliminary Interview with Dan Becker--February 21, 1995

The Sierra Club

Page 2

energy supply can be increased from the current $9 \%$ level. We are only guessing at leaps, but the evidence for their potential is there. For example:

- The South Coast Energy Management District is demonstrating electric vehicles powered by a solar power station.

- Photovoltaics are now producing electricity at 7 cents per kilowatt hour. Large companies like Texas Instruments, some utilities and Japanese companies are marketing PV's.

- Some hydro (particularly low head) is beneficial. Refitting existing dams could increase hydro's contribution.

We have an educated citizenry that is increasingly concerned about the environment. The New York Times has been polling people, asking whether environment is an important issue that should be dealt with at any cost. In 1974, $25 \%$ said yes; recently, $82 \%$ said yes. Children are particularly aware of the environment. Even their television programs reflect this. "Captain Planet", a cartoon program, teaches kids that they have responsibility to teach others about the environment. Conservative college students support environmental initiatives and believe it is expensive to waste. We have spent the last 25 years educating; now that the education is done, change will be easier. The Contract for America does not overtly gut environmental progress, but its effects could slow the agenda; overall, however, the momentum for a better environment will override the Contract.

On the international side, the U.S. and OECD countries which represent $40 \%$ of the problem are obligated to provide assistance. Frigidaire, for example, can sell efficient refrigerators at concessionary rates now so that they can sell dishwashers later. Licensing efficient technologies to China will today will allow companies to come back later.

Joint implementation agreements are not an appropriate means for achieving these goals. They are unenforceable because they are basically paper agreements with no baseline emission inventory and no policing mechanism. Many of the credits are for actions that would have occurred anyway. And, these agreements avoid the benefits of increased energy efficiency and blunt the thrust for technology advancement. Pushing the frontiers of technology has payoffs, as illustrated by the progress in photovoltaics, solar, cars and others.

\section{Suggested Contacts}

Friends of the Earth -- Ralph DiGenero, Economist in charge of the Green Scissors Program U.S. PIRG -- Ann Aurelio, Staff Scientist (202) 546-9707 
DRAFT Interview with Ned Helme -- February 28, 1995

Center for Clean Air Policy

Page 1

\section{Critical Environmental Issues for Coal as We Approach 2020}

Coal is under significant environmental pressure and therefore has a clouded future. The most significant cause of this pressure is concern about global climate change. In addition, other major environmental concerns include:

- Mercury and air toxics.

- Fine particulates

- A potential short term $\mathrm{SO}_{2}$ standard

- Ozone non-attainment and therefore $\mathrm{NO}_{\mathrm{x}}$ controls

Science is likely to support regulation of mercury and other air toxics. The focus is on mercury, which volatizes at about $75^{\circ} \mathrm{F}$. Only $20 \%$ is removed by scrubbers. Other potential control strategies include carbon absorption and precleaning of coal. There has not been an aggressive program for developing control strategies. Coal switching may also be an alternative; Rocky Mountain coal might be substituted for Appalachian coal to reduce emissions.

Both the potential fine particulates and short term $\mathrm{SO}_{2}$ standard would be based on health effects. Further $\mathrm{NO}_{\mathrm{X}}$ control is likely because it may be one of the lowest cost options for attaining ozone standards. For example, it appears that $\mathrm{NO}_{\mathrm{X}}$ emissions in the Ohio River Valley are contributing to ozone non-attainment in the Chicago area. The lowest cost control strategy may be to retrofit the Ohio River coal burning units, but there is a debate on who should pay for them.

If risk assessment is introduced, changes in the standards for toxics, $\mathrm{SO}_{2}, \mathrm{NO}_{\mathrm{X}}$ and fine particulates might not be enacted if the assessments demonstrated that the improvement in health did not outweigh the costs of further control.

Concerns about climate change drive the move away from coal. The Center for Clean Air Policy has looked at technologies like carbon dioxide scrubbers and carbon dioxide injection into gas wells and worked with the Cool Water facility to reduce carbon dioxide emissions. Reducing contributors to global climate change by $60 \%$ is a 50 year and very expensive problem. Environmental controls to date have added $40 \%$ to the cost of using coal in the United States. Even if the U.S. wanted to incur the costs of reducing carbon dioxide and methane emissions, the climate change problem is a global one with large transfer implications. Since the problem is long term, the political system will have a difficult time responding. Also, the effects may not be visible until they are too serious to control. Adaptation may become part of the response strategy.

Joint Implementation Agreements are a strategy for finding the lowest cost methods of control. Carbon dioxide control will be more expensive for industrialized countries. Buying greater efficiency in other countries may be the lowest cost alternative. Work that CCAP is doing in Czechoslovakia to control emissions indicates that environmental investments abroad can provide a reasonable rate of return (with a slightly lower hurdle rate than traditional investments). Joint Implementation Agreements provide the opportunity to free up market opportunities to make money from "green" investments. In the developing world, supply efficiency can be attained with relative ease; demand side management measures, on the other hand, are more difficult to finance. 
DRAFT Interview with Ned Helme -- February 28, 1995

Center for Clean Air Policy

Page 2

\title{
Role of Technology in Meeting Environmental Requirements
}

It is important to continue to develop technologies that will make the costs of control reasonable. Vendors, for example, have greatly cut the costs of scrubber technology. The 1989 Clean Air Act Amendments capped the cost sulfur dioxide emission trades at $\$ 1500$ per ton, out of concern that the independent power producers would not be able to afford to buy them. Because of the cost reductions, sulfur dioxide is trading in the range of $\$ 130$ per ton for Phase I credits and $\$ 150$ per ton for Phase II credits. The DOE financed research on fluidized bed combustion and flue gas clean up have contributed to this reduction in costs. $\mathrm{NO}_{\mathrm{x}}$ reduction is also an example of successful technology development. It is important to stay on the cutting edge of new technologies such as carbon absorption.

\section{Role of Coal in the Twenty-First Century}

In the United States, we can expect to use less coal over time as environmental standards favor natural gas and other technologies. By 2020, we can expect less intensive coal use and greater portions of natural gas, biomass, possibly photovoltaics, solar and wind in the energy mix. AEP is constructing a $400 \mathrm{MW}$ wind powered facility in Central West Virginia that is made economically feasible by a 2 cent per KWH credit and another wind facility is planned for the western slope of Wyoming.

In the international market, we can expect more coal use in India and China, with the potential for driving up total global coal use and carbon emissions. Wherever possible, gas use will be used. Even though it is also a contributor to global climate change, the carbon emissions are only half on an energy equivalent basis. Eventually, non carbon emitting technologies will be substituted for natural gas.

\section{Suggested Contacts}

\author{
EPRI -- Kurt Yager \\ Wisconsin Electric Power; PacifiCorp \\ John Sununu \\ Consolidation Coal -- Dick Kearch \\ Massey Coal - Jerry Eister \\ Arco Coal -- Terry O'Connell \\ NRDC -- David Hawkins \\ Mike Clark (Montana) \\ League of Conservation Voters -- Jim Matty \\ World Resources Institute -- Roger Dower \\ Research Cottrell (New Jersey)
}

